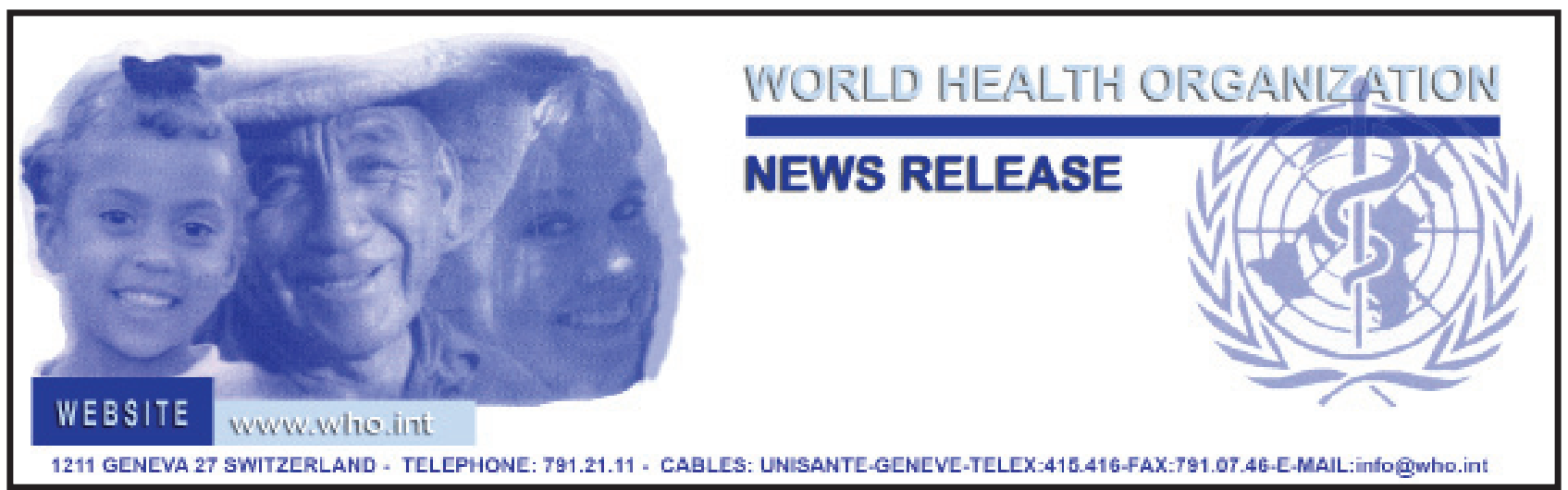

\title{
NEARLY 30 MILLION SICK AND PREMATURE NEWBORNS IN DIRE NEED OF TREATMENT EVERY YEAR
}

13 December 2018 News Release NEW DELHI/ GENEVA /NEW YORK - Nearly 30 million babies are born too soon, too small or become sick every year and need specialized care to survive, according to a new report by a global coalition that includes UNICEF and WHO.

"When it comes to babies and their mothers, the right care at the right time in the right place can make all the difference," said Omar Abdi, UNICEF Deputy Executive Director. "Yet millions of small and sick babies and women are dying every year because they simply do not receive the quality care that is their right and our collective responsibility."

The report, Survive and Thrive: Transforming care for every small and sick newborn, finds that among the newborn babies most at risk of death and disability are those with complications from prematurity, brain injury during childbirth, severe bacterial infection or jaundice, and those with congenital conditions. Additionally, the financial and psychological toll on their families can have detrimental effects on their cognitive, linguistic and emotional development.

"For every mother and baby, a healthy start from pregnancy through childbirth and the first months after birth is essential," said Dr Soumya Swaminathan, Deputy Director General for Programmes at WHO. "Universal health coverage can ensure that everyone - including newborns - has access to the health services they need, without facing financial hardship. Progress on newborn health care is a win-win situation - it saves lives and is critical for early child development thus impacting on families, society, and future generations."

Without specialized treatment, many at-risk newborns won't survive their first month of life, according to the report. In 2017, some 2.5 million newborns died, mostly from preventable causes. Almost two-thirds of babies who die were born premature. And even if they survive, these babies face chronic diseases or developmental delays. In addition, an estimated 1 million small and sick newborns survive with a long-term disability.

With nurturing care, these babies can live without major complications. The report shows that by 2030, in 81 countries, the lives of 2.9 million women, stillborns and newborns can be saved with smarter strategies. For example, if the same health team cares for both mother and baby through labour, birth and beyond, they can identify problems early on. 
In addition, almost 68 per cent of newborn deaths could be averted by 2030 with simple fixes such as exclusive breastfeeding; skin-to-skin contact between the mother or father and the baby; medicines and essential equipment; and access to clean, well-equipped health facilities staffed by skilled health workers. Other measures like resuscitating a baby who cannot breathe properly, giving the mother an injection to prevent bleeding, or delaying the cutting of the umbilical cord could also save millions.

According to the report, the world will not achieve the global target to achieve health for all unless it transforms care for every newborn. Without rapid progress, some countries will not meet this target for another 11 decades. To save newborns, the report recommends:

- Providing round-the-clock inpatient care for newborns seven days a week.

- Training nurses to provide hands-on care working in partnership with families.

- Harnessing the power of parents and families by teaching them how to become expert caregivers and care for their babies, which can reduce stress, help babies gain weight and allow their brains to develop properly.

- Providing good quality of care should be a part of country policies, and a lifelong investment for those who are born small or sick.

- Counting and tracking every small and sick newborn allows managers to monitor progress and improve results.

- Allocating the necessary resources, as an additional investment of US\$ 0.20 cents per person can save 2 of every 3 newborns in low- and middle-income countries by 2030.

Almost three decades ago, the Convention on the Rights of the Child guaranteed every newborn the right to the highest standard of health care, and it is time for countries around the world to make sure the legislative, medical, human and financial resources are in place to turn that right into a reality for every child, the report says.

Available from: https://www.who.int/news-room/detail/13-12-2018-nearly-30-million-sick-and-prematurenewborns-in-dire-need-of-treatment-every-year 